Document downloaded from:

http://hdl.handle.net/10251/165285

This paper must be cited as:

Rivero-Crespo, MÁ.; Tejeda-Serrano, M.; Perez-Sánchez, H.; Cerón-Carrasco, JP.; Leyva Perez, A. (2020). Intermolecular Carbonyl-olefin Metathesis with Vinyl Ethers Catalyzed by Homogeneous and Solid Acids in Flow. Angewandte Chemie International Edition. 59(10):3846-3849. https://doi.org/10.1002/anie.201909597

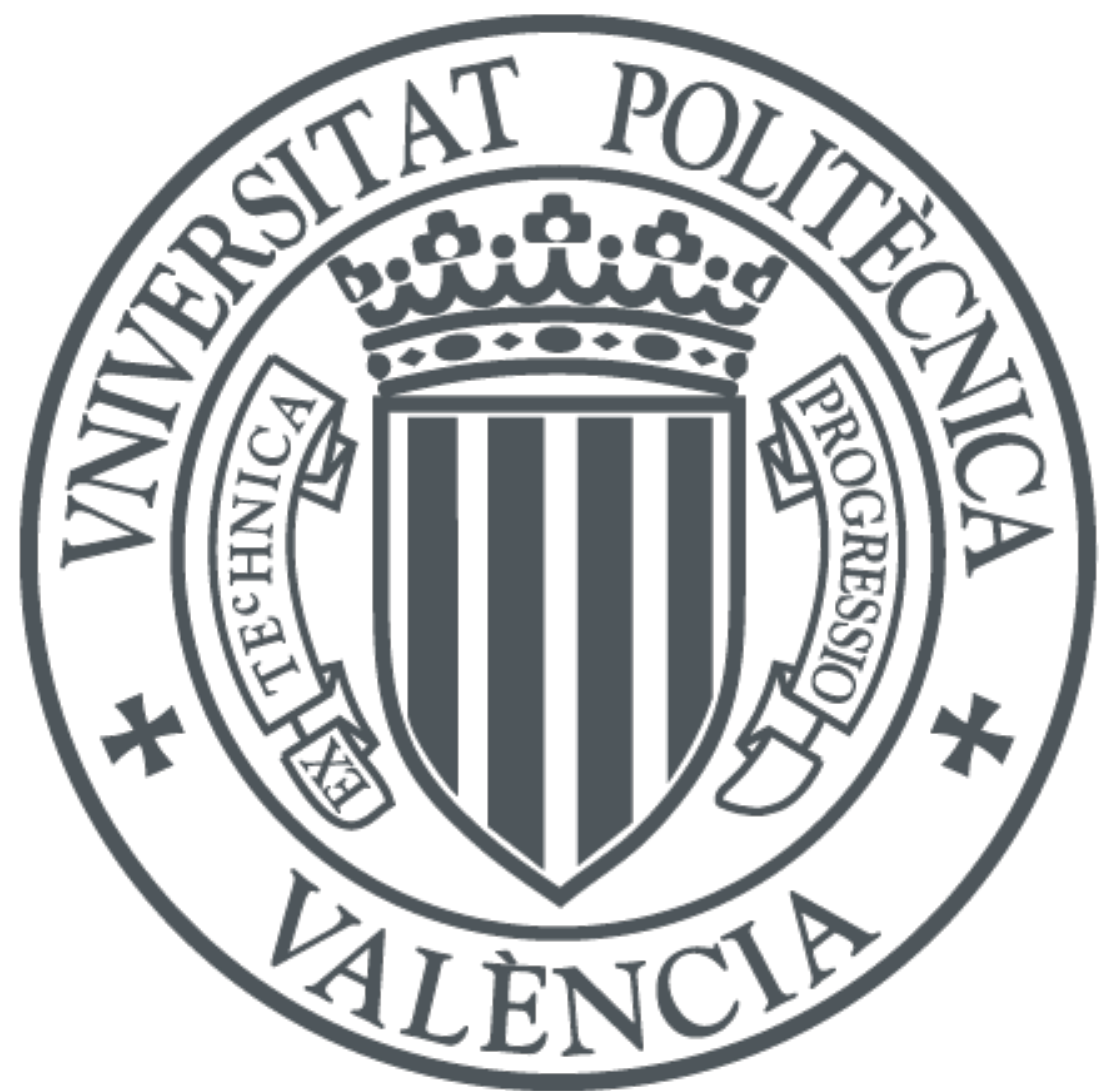

The final publication is available at

https://doi.org/10.1002/anie.201909597

Copyright John Wiley \& Sons

Additional Information

This is the peer reviewed version of the following article: M. A. Rivero-Crespo, M. TejedaSerrano, H. Pérez-Sánchez, J. P. Cerón-Carrasco, A. Leyva-Pérez, Angew. Chem. Int. Ed. 2020, 59, 3846, which has been published in final form at https://doi.org/10.1002/anie.201909597. This article may be used for non-commercial purposes in accordance with Wiley Terms and Conditions for Self-Archiving. 


\title{
Intermolecular Carbonyl-Olefin Metathesis with Vinyl Ethers Catalyzed by Homogeneous and Solid Acids in Flow.
}

\author{
Miguel Ángel Rivero-Crespo, ${ }^{\$[a]}$ María Tejeda-Serrano, ${ }^{\text {[a] }}$ Horacio Pérez-Sánchez, ${ }^{[b]}$ José Pedro \\ Cerón-Carrasco ${ }^{[b]}$ and Antonio Leyva-Pérez. ${ }^{[a]}$
}

\begin{abstract}
The carbonyl-olefin metathesis reaction has experienced significant advances in the last seven years with new catalysts and reaction protocols. However, most of these procedures involve soluble catalysts for intramolecular reactions in batch. Here, we show that recoverable, inexpensive, easy-handling, non-toxic and widely available simple solid acids, such as the aluminosilicate montmorillonite, catalyze the intermolecular carbonyl-olefin metathesis of aromatic ketones and aldehydes with vinyl ethers inflow, to give alkenes with complete trans stereoselectivity in multigram yields. Experimental and computational data support a mechanism based on a carbocation-induced Grob fragmentation. These results open the way for the industrial implementation of carbonyl-olefin metathesis over solid catalysts in continuous mode, which is in turn the origin and main application still of the parent alkene-alkene cross-metathesis.
\end{abstract}

The direct transformation of carbonyl compounds into alkenes is now moving from stoichiometric and waste-generating Wittigtype protocols to more efficient catalytic processes. ${ }^{[1]}$ Among them, the carbonyl-olefin metathesis reaction stands out by the availability and low price of the starting materials, redox neutrality, and simplicity of retrosynthetic disconnections, akin to parent alkene cross-metathesis. ${ }^{[2]}$ However, in contrast to the latter, only one solid precursor has apparently been reported for the carbonyl-olefin metathesis, ${ }^{[3,4]}$ with just two substrates in $15-30 \%$ yields. ${ }^{[5]}$ The lack of solid catalysts for the carbonyl olefin metathesis comes from the extreme acidity required for the catalyst to increase the reaction rate towards the final carbonyl/alkene products, i.e. the $\mathrm{pK}_{\mathrm{a}}$ of soluble acids employed so far is well below 0 , particularly those involving intermolecular reactions. ${ }^{[6,7]}$ Thus, it is difficult to think in a conventional solid with the level of acidity required for the transformation which, besides, does not concomitantly trigger other more favorable acid catalyzed reactions such as the aldol, alkene and Prins couplings. ${ }^{[8]}$ To circumvent these drawbacks, we envisaged the use of vinyl ethers as alkene partners in the intermolecular

[a] Dr. M. Á. Rivero-Crespo, M. Tejeda-Serrano, Dr. A. Leyva-Pérez. Instituto de Tecnología Química (UPV-CSIC), Universitat Politècnica de València-Consejo Superior de Investigaciones Científicas, Avda. de los Naranjos s/n, 46022 Valencia, Spain. E-mail: anleyva@itq.upv.es

[b] Dr. H. Pérez-Sánchez, Dr. J. P. Cerón-Carrasco.

Structural Bioinformatics and High Performance Computing Research Group (BIO-HPC). Universidad Católica de Murcia (UCAM), Spain.

$\S$ These authors contributed equally to the work

Supporting information for this article including experimental section, additional computational details, compound

characterization, NMR copies and additional Figures S1-S10 and

Tables S1-S7, is given via a link at the end of the document.

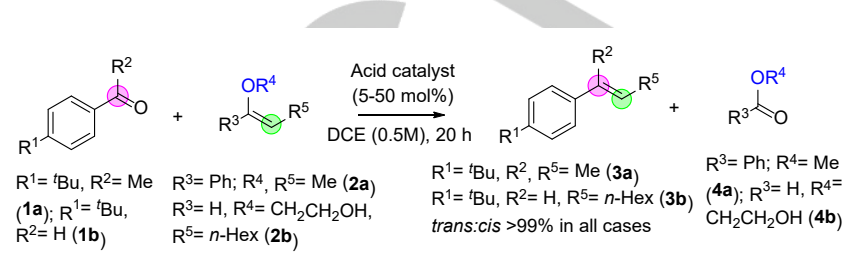

Table 1. Selected results of the catalyst screening for the carbonyl-olefin metathesis of ketones $\mathbf{1 a}$ or aldehyde $\mathbf{1} \mathbf{b}$ with vinyl ethers $\mathbf{2 a - b}$ (1.5 eq.) in batch (see complete screening in $\mathrm{SI}$ ). Isolated yields after complete consumption of $2 \mathrm{a}-\mathrm{b}$ or $20 \mathrm{~h}$ reaction time.

\begin{tabular}{|c|c|c|c|c|}
\hline Entry & Catalyst (mol\%) & $\begin{array}{c}\mathrm{T} \\
\left({ }^{\circ} \mathrm{C}\right)\end{array}$ & $\begin{array}{c}\text { Carbonyl/vin } \\
\text { yl ether }\end{array}$ & $\begin{array}{l}\text { Product } \\
\text { (\% yield) }\end{array}$ \\
\hline $1^{[\mathrm{a}]}$ & $\mathrm{FeCl}_{3}(50)$ & 25 & $1 a / 2 a$ & $3 a(51)$ \\
\hline 2 & & 25 & $1 b / 2 b$ & $3 b(24)$ \\
\hline 3 & 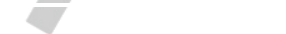 & 60 & $1 b / 2 b$ & $3 b(25)$ \\
\hline 4 & $\mathrm{BF}_{3} \cdot \mathrm{OEt}_{2}(50)$ & 25 & $1 \mathrm{a} / 2 \mathrm{a}$ & $3 a(56)$ \\
\hline 5 & & 25 & $1 b / 2 b$ & $3 b(64)$ \\
\hline 6 & HOTf $(50)$ & 25 & $1 a / 2 a$ & $3 a(45)$ \\
\hline 7 & HOTf (10) & 25 & $1 b / 2 b$ & $3 b(56)$ \\
\hline 8 & Nafion $^{\mathrm{TM}}(50)$ & 60 & $1 b / 2 b$ & $3 b(58)$ \\
\hline 9 & Amberlyst A15 (50) & 60 & $1 b / 2 b$ & $3 b(38)$ \\
\hline 10 & Zeolite HUSY (50) & 60 & $1 b / 2 b$ & $3 b(6)$ \\
\hline 11 & & 100 & $1 b / 2 b$ & 3b (38) \\
\hline 12 & MCM-41 (50) & 60 & $1 b / 2 b$ & $3 \mathbf{b}(16)$ \\
\hline 13 & Montmorillonite K10 (50) & 60 & $1 b / 2 b$ & $3 b(45)$ \\
\hline $\begin{array}{c}14 \\
15^{[b]}\end{array}$ & Montmorillonite K10 (5) & $\begin{array}{l}100 \\
100\end{array}$ & $\begin{array}{l}1 b / 2 b \\
1 b / 2 b\end{array}$ & $\begin{array}{l}\text { 3b (65) } \\
\text { 3b (87) }\end{array}$ \\
\hline
\end{tabular}

[a] No reaction with anhydrous $\mathrm{FeCl}_{3}$. [b] In-flow reaction: $1 \mathrm{~b}$ in toluene $0.5 \mathrm{M}$, $0.01 \mathrm{ml} \cdot \mathrm{min}^{-1}$ over $8 \mathrm{~h}$ at $120{ }^{\circ} \mathrm{C}$ (see Figure 1 for a $40 \mathrm{~h}$ reaction time experiment)

carbonyl-olefin metathesis, since the generation of unreactive esters instead of competing aldehyde/ketone as by-products may shift the equilibrium towards the products, facilitate the catalytic action not only of metal salts but also of simple solids acids, and enable and easy purification of the alkene products by column chromatography (Figure S1). ${ }^{[9]}$

Table 1 shows selected catalytic results for the metathesis reaction between aromatic ketones and aldehydes $\mathbf{1} \mathbf{a}-\mathbf{b}$ with vinyl

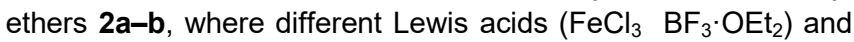
Brönsted acids (HOTf) give significant yields of trans alkenes 3ab at room temperature (entries 1-7, no cis alkenes detected by gas chromatography, GC; see also Tables S1-S3 and Figures S2-S3). Notice that these metal salts are well-known active 
catalysts for intramolecular carbonyl olefin metathesis but not for intermolecular reactions. ${ }^{[10]}$

A freshly open sample of anhydrous $\mathrm{FeCl}_{3}$, managed in a glovebox, does not catalyze the metathesis reaction, and when a $50 \mathrm{~mol} \%$ of water is added, the metathesis reaction starts. Addition of a proton quencher such as di-tert-butyl pyridine to the reaction medium (50 mol\%) stops not only the metathesis but also any other parasite reaction (aldol, hydrolysis of the vinyl ether,...), for all the soluble catalysts tested. These results indicate that in-situ formed protons are also the catalytically active species also during the metal salt-catalyzed intermolecular carbonyl olefin metathesis, and with this in mind and the positive results obtained for soluble Brönsted acids, a variety of commercially-available solid acids (entries 8-15) were tested as catalysts for the metathesis (Table S4). ${ }^{[11]}$ The results in Table 1 show that all the solid Brönsted acid catalysts tested gave similar product yields and selectivity than the soluble acids for alkene product $\mathbf{3 b}$, including the widely available, inexpensive and non-toxic pillared clay montmorillonite K10 (<10 euros/kg, entries 14-15). The ester by-products $\mathbf{4 a - b}$ are completely unreactive under the present reaction conditions for any catalyst, according to control experiments, and the purification of the final alkene products by column chromatography becomes easier in the absence of additional alkene/aldehydes/ketones in the mixture. These results support our starting hypothesis that vinyl ethers are suitable alkene partners for the intermolecular carbonyl-olefin metathesis.

A convenient and productive way to circumvent side reactions during the intermolecular metathesis could be to perform the reaction in flow over a fixed-bed reactor with a solid catalyst, in order to rapidly separate the acid catalyst from the reaction mixture after the metathesis reaction. Gratifyingly, a consistent good yield of $\mathbf{3 b}(70-95 \%, G C)$ over $8 \mathrm{~h}$ in-flow reaction time was obtained with fixed-bed montmorillonite K10 (entry 15 in Table 1). Figure 1 (top) shows that the procedure with montmorillonite $\mathrm{K} 10$ in continuous mode is also suitable to prepare a variety of trans alkenes in high yields after just $1 \mathrm{~h}$ on stream time (condition A), generally in better yields than with soluble $\mathrm{BF}_{3} \cdot \mathrm{OEt}_{2}$ catalyst in batch (condition $\mathrm{B}$ ). The main side reaction corresponds to vinyl ether hydrolysis, which explains the better reactivity of in-situ generated vinyl ethers from acetals $2 \mathbf{a}-\mathbf{g}$ (see also Figure S4). ${ }^{[12]}$ Good to moderate yields are generally obtained, and some functional groups are shown to be tolerated, including halides (compounds $\mathbf{3 g}, \mathbf{3} \mathbf{i}-\mathbf{I}$ ), aromatic ethers $(\mathbf{3 g})$, esters $(\mathbf{3 n})$, amides (3t), thioethers (3v), and other alkenes $(\mathbf{3} \mathbf{x})$.

Figure 1 (bottom) shows that montmorillonite $\mathrm{K} 10$ is still active after $40 \mathrm{~h}$ in-flow, which gives a turnover number (TON) of 150 , significantly higher than homogeneous catalysts, ${ }^{[3]}$ and backs up the robustness of the solid catalyst to give access to multi-gram amounts of alkene $\mathbf{3 b}$. Besides, selectivity towards the alkene product is consistently higher than $90 \%$, highlighting the benefits of performing the reactions in flow with a solid catalyst (see also Table S5).

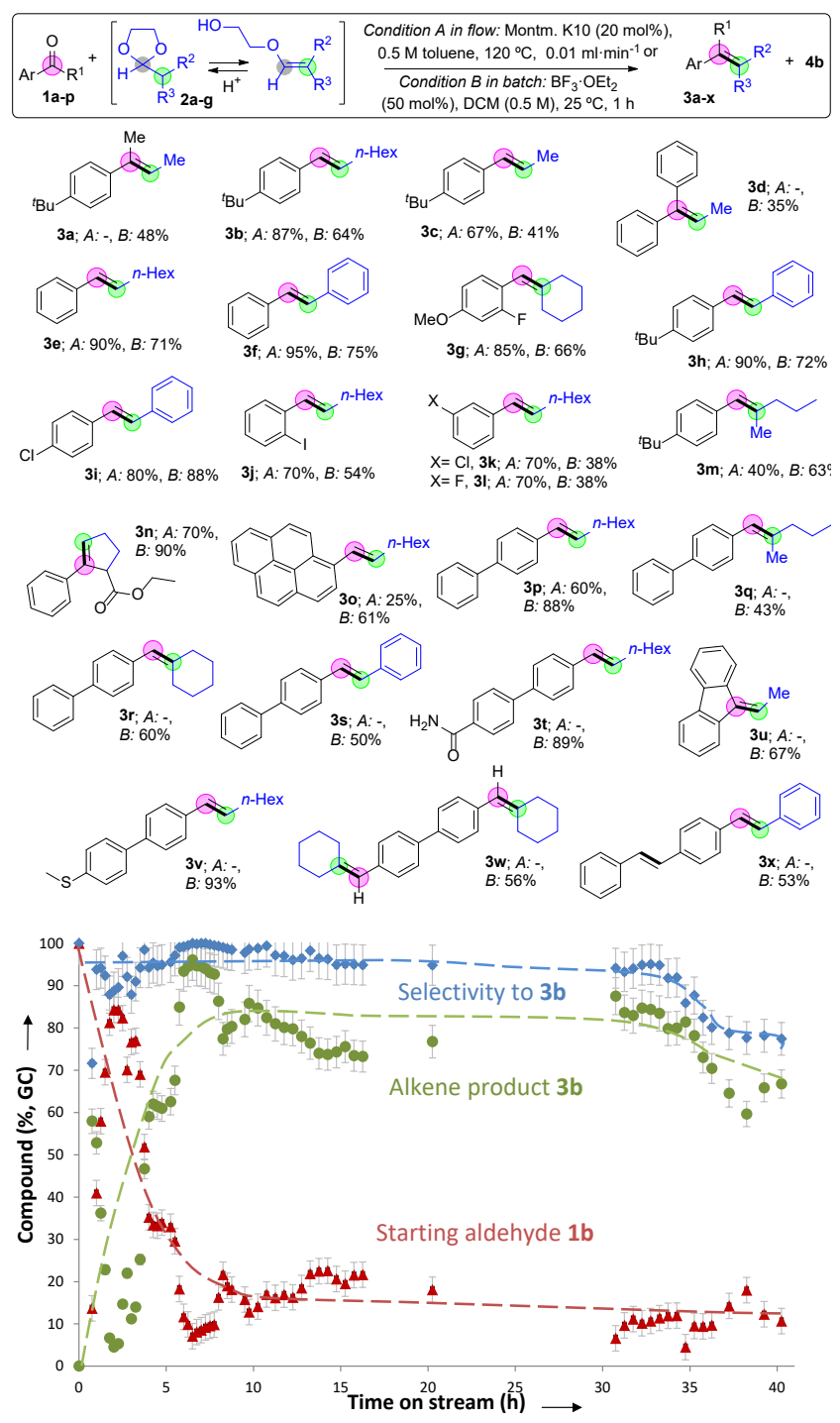

Figure 1. Top: Carbonyl olefin metathesis reactions of aryl aldehydes $\mathbf{1 b}, \mathbf{d}-\mathbf{i}$ with in-situ formed vinyl ether $\mathbf{2} \mathbf{d}-\mathbf{g}$ catalyzed by montmorillonite K10 (A) or $\mathrm{BF}_{3} \cdot \mathrm{OEt}_{2}$ (B) under the indicated reaction conditions (top). Bottom: Kinetic profile for the metathesis reaction between $\mathbf{1 b}$ and $\mathbf{2} \mathbf{d}$ in a fixed-bed tubular reactor with montmorillonite $\mathrm{K} 10$ catalyst $\left(0.5 \mathrm{M}\right.$ toluene, $0.01 \mathrm{ml} \cdot \mathrm{min}^{-1}$ over 40 h at $120^{\circ} \mathrm{C}$, bottom). Colour scheme: starting aldehyde $1 \mathrm{~b}$ in red, alkene product $\mathbf{3 b}$ in green, selectivity in blue. Lines are a guide to the eye. Error bars account for a $5 \%$ uncertaintity.

Figure 2 shows that the activation enthalpy values for the metathesis reaction between $\mathbf{1 b}$ and $\mathbf{2 b}$ with different Brönsted acids, correlate well with the $\mathrm{pK}_{\mathrm{a}}$ of the catalyst for the homogeneous acids and also for montmorillonite $\mathrm{K} 10$, and deviate towards higher values for other solid acids (see also Figure S5, and Figure S6 for entropy correlation). ${ }^{[1 \mathrm{~b}]}$ Kinetic experiments at different stirring rates show that the reaction is controlled by diffusion for all solid catalysts except for montmorillonite $\mathrm{K} 10,{ }^{[13]}$ which strongly supports that the reaction enthalpy is directly related to proton strength. 


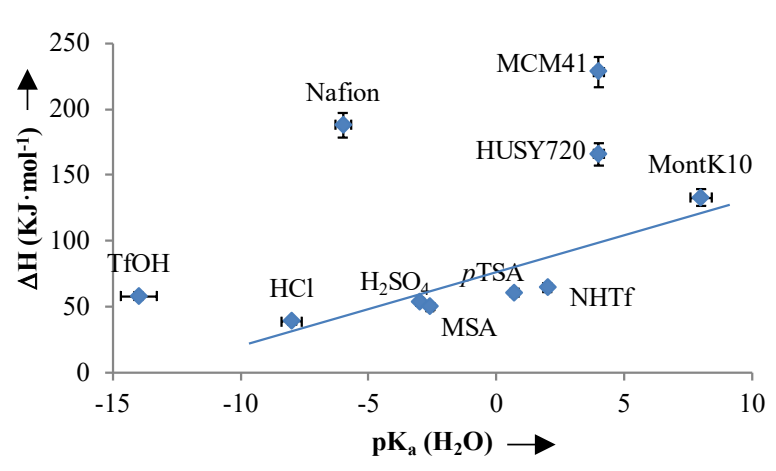

Figure 2. Activation enthalpy $\left(\mathrm{KJ} \cdot \mathrm{mol}^{-1}\right)$ for the carbonyl-olefin metathesis of $\mathbf{1 b}$ with $\mathbf{2 b}$ with different acids. Aluminosilicates were dried under vacuum at $250{ }^{\circ} \mathrm{C}$ for $3 \mathrm{~h}$ before reaction. Linear regression, $\mathrm{R}^{2}=0.88$. Error bars account for a $5 \%$ uncertaintity.

Figure 3 (top) shows experimental and computational evidences about the mechanism of the reaction (see also Figure S7 and Table S6). A Hammett plot with different para-substituted acetophenones (Figure S8) gives $\rho=-2.7$, which indicates building of positive charge on the carbonyl group in the ratedetermining step of the reaction. No traces of oxetane could be detected during reaction, and the preparation of the postulated oxetane intermediate showed elusive in our hands when using the most accepted photochemical methods, in accordance with the lack of efficient reported methods for $\alpha$-hydroxyoxetanes. ${ }^{[14]}$ These results point to the formation of a cationic intermediate during the metathesis reaction. Indeed, the activation entropy for homogeneous acids is negative (the expected value for an associative transition state) but positive for solids, including montmorillonite $\mathrm{K} 10$, which is consistent with an extra-stabilized carbocation transition state within the anionic aluminosilicate framework (see Figure S6). ${ }^{[11 \mathrm{~b}]}$

Figure 3 also shows that the isotopically labelled ketone 1d${ }^{18} \mathrm{O}^{[15]}$ gives an ester by-product that does not contain any labelled oxygen atom, while the addition of one equivalent of $\mathrm{H}_{2}{ }^{18} \mathrm{O}$ in the reaction medium generates a significant amount of isotopically labelled ester. Control experiments without 2a confirm that no $O$ atom exchange occurs in the absence of the vinyl ether (Figure S9). These results unveil that the alkene product actually comes from a water-mediated carbonyl-olefin metathesis and not from a direct transferring of the carbonyl oxygen atom, which seems to be accepted in the literature as a formal carbonyl-olefin metathesis reaction ${ }^{[7 c]}$ (see also Figure S10 and Table S7). ${ }^{[16]}$ These results strongly support the participation of external alcohol or water molecules as nucleophiles during reaction.

Figure 3 (middle) shows a reaction mechanism consistent with all the experimental data above commented. The first step is the nucleophilic attack of the vinyl ether to the proton-activated carbonyl group, which, after hemiacetal formation and acidcatalyzed dehydration, generates a suitable anti- $\alpha$ hydroxyl carbocation to undergo a Grob fragmentation ${ }^{[17]}$ and give the final trans alkene. ${ }^{[18]}$ Density functional theory (DFT) calculations were then conducted for the proton-catalyzed metathesis reaction

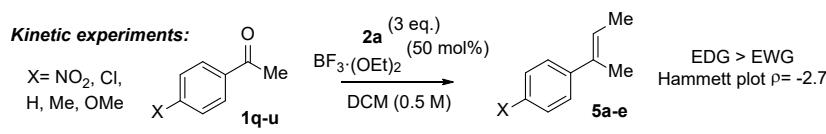

$$
\text { Isotopic experiments: }
$$
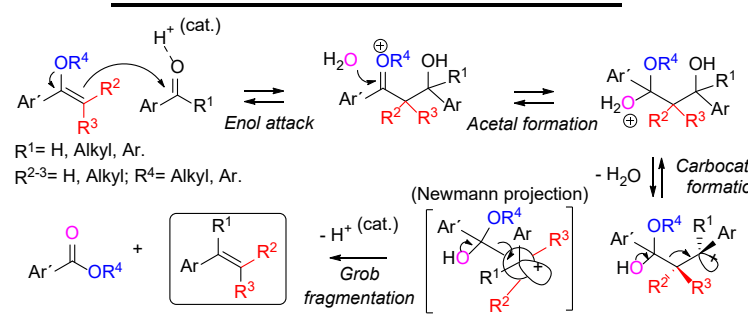

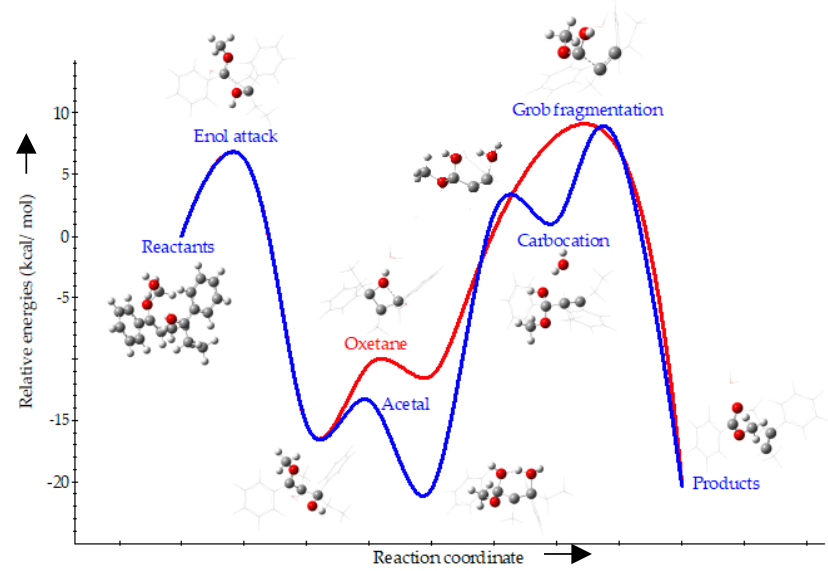

Figure 3. Experimental evidences (top) and plausible reaction mechanism (middle) for the acid-catalyzed metathesis reaction between aromatic aldehydes/ketones and vinyl ethers. Computed energy profile (bottom) for the proton-catalyzed metathesis of $\mathbf{1 b}$ and $\mathbf{2 a}$; color scheme for atoms: carbon in grey, oxygen in red and hydrogen in white. Blue and red curves stand for the reaction through the acetal and oxetane intermediates, respectively.

between $\mathbf{1 b}$ and $\mathbf{2 a}$, without imposing any geometrical restriction to reactants, products and transition states, and with vibrational calculations to confirm the nature of the located minima in the potential energy surface, including solvent effects. ${ }^{[19]}$ Figure 3 (bottom) shows that the most favorable mechanism, highlighted in blue, consists in the proton-catalyzed nucleophilic attack of $2 \mathrm{a}$ to $1 \mathrm{~b}$ through a barrier of $6.3 \mathrm{kcal}^{-1}$ to give the thermodynamically favorable aldol-like adduct, $15.4 \mathrm{kcal} \mathrm{mol}^{-1}$ more stable than the parent reactants and in equilibrium with the corresponding hemi-acetal (only differing in $2.0 \mathrm{kcal} \mathrm{mol}^{-1}$ ), which then triggers a proton transfer to the vicinal hydroxyl group to give the carbocation. The latter reaction is the limiting step of the process, with an energetic barrier of $22.4 \mathrm{kcal} \mathrm{mol}^{-1}$, after which the Grob fragmentation proceeds with a barrier of $5.9 \mathrm{kcal} \mathrm{mol}^{-1}$ to give the final trans alkene product $\left(20.5 \mathrm{kcal} \mathrm{mol}^{-1}\right.$ more stable than $\mathbf{1 b}$ and $\mathbf{2 a}$ ). The alternative mechanism through the oxetane, highlighted in red, is kinetically impeded by $5.1 \mathrm{kcal} \mathrm{mol}^{-1}$ compared to acetal formation, and with a reversion energy barrier of only $1 \mathrm{kcal} \mathrm{mol}^{-1}$ from the oxetane to the aldol adduct. All 
accumulated experimental and theoretical evidences strongly support carbocation formation and later Grob fragmentation as plausible mechanism for this metathesis reaction. ${ }^{[6 a, 7 c]}$

In conclusion, the intermolecular carbonyl-olefin metathesis of aromatic aldehydes and ketones with vinyl ethers catalyzed by fixed-bed Brönsted solid acids or, alternatively, by metal salts or conventional Brönsted acids in solution, has been accomplished. Mild solid acids, particularly the aluminosilicate montmorillonite $\mathrm{K} 10$, catalyze the intermolecular reaction with vinyl ethers by shifting the equilibrium towards the alkene products and also by stabilizing intermediate carbocations formed during reaction. These results enable the synthesis of trans alkenes in continuous flow by intermolecular carbonyl-olefin metathesis, with potential applications as simple building blocks in chemical industry. ${ }^{[20]}$

\section{Acknowledgements}

Financial support by MINECO through the Severo Ochoa program (SEV-2016-0683), Excellence program (CTQ 201786735-P, CTQ 2017-87974-R), Retos Col. (RTC-2017-63315) and also "Convocatoria 2014 de Ayudas Fundación BBVA a Investigadores y Creadores Culturales" is acknowledged. M. A. R.-C. and M. T.-S. thank ITQ for the concession of a contract. This research was partially supported by the supercomputing infrastructure of Poznan Supercomputing Center.

Keywords: carbonyl-olefin metathesis $\cdot$ montmorillonite K10 • heterogeneous catalysis $\bullet$ in-flow reactions $\bullet$ vinyl ethers

[1] M. R. Becker, R. B. Watson, C. S. Schindler, Chem. Soc. Rev. 2018, 47, 7867-7881.

[2] a) A. K. Griffith, C. M. Vanos, T. H. Lambert, J. Am. Chem. Soc. 2012, 134, 18581-18584; b) J. R. Ludwig, P. M. Zimmerman, J. B. Gianino, C S. Schindler, Nature 2016, 533, 374-379; c) J. R. Ludwig, S. Phan, C. C. McAtee, P. M. Zimmerman, J. J. Devery 3rd, C. S. Schindler, J. Am. Chem. Soc. 2017, 139, 10832-10842.

[3] For reviews on carbonyl olefin metathesis see a) J. R. Ludwig, C. S Schindler, Synlett 2017, 28, 1501-1509; b) T. H. Lambert, Synlett 2019, ahead of print.

[4] For examples of solid-catalyzed low-temperature alkene metathesis see a) V. Mougel, K.-W. Chan, G. Siddiqi, K. Kawakita, H. Nagae, H. Tsurugi, K. Mashima, O. Safonova, C. Copéret, ACS Cent. Sci. 2016, 2 (8), 569576; b) M. D. Korzynski, D. F. Consoli, S. Zhang, Y. Román-Leshkov, M. Dinca, J. Am. Chem. Soc. 2018, 140, 6956-6960.

[5] H.-P. van Schaik, R.-J. Vijn, F. Bickelhaupt, Angew. Chem. Int. Ed. 1994, 33, 1611-1612.

[6] For pure Bronsted acid-catalyzed reactions see a) J. R. Ludwig, R. B. Watson, D. J. Nasrallah, J. B. Gianino, P. M. Zimmerman, R. A. Wiscons C. S. Schindler, Science 2018, 361(6409), 1363-1369; b) L. Catti, K. Tiefenbacher, Angew. Chem. Int. Ed. 2018, 57(44), 14589-14592.
[7] For intermolecular reactions see a) N. V. Ramesh, J. Bah, J. Franzén, Eur. J. Org. Chem. 2015, 1834-1839; b) S. Ni, J. Franzén, Chem Commun. 2018, 54, 12982-12985; c) L. Pitzer, F. Sandfort, F. StriethKalthoff, F. Glorius, Angew. Chem. Int. Ed. 2018, 57(49),16219-16223.

[8] J. D. Lewis, S. Van de Vyver, Y. Román-Leshkov, Angew. Chem. Int Ed. 2015, 54, 9835-9838.

[9] a) F. R. Fortea-Perez, M. Mon, J. Ferrando-Soria, M. Boronat, A Leyva-Perez, A. Corma, J. M. Herrera, D. Osadchii, J. Gascon, D Armentano, E. Pardo, Nat. Mater. 2017, 16, 760-766; b) J. OliverMeseguer, M. Boronat, A. Vidal-Moya, P. Concepcion, M. A. RiveroCrespo, A. Leyva-Perez, A. Corma, J. Am. Chem. Soc. 2018, 140(9), 3215-3218; c) M. A. Rivero-Crespo, M. Mon, J. FerrandoSoria, C. W. Lopes, M. Boronat, A. Leyva-Perez, A. Corma, J. C Hernandez-Garrido, E. Lopez-Haro, J. J. Calvino, E. V. RamosFernandez, D. Armentano, E. Pardo, Angew. Chem. Int. Ed. 2018, 57(52), 17094-17099; d) M. Tejeda-Serrano, M. Mon, B. Ross, F Gonell, J. Ferrando-Soria, A. Corma, A. Leyva-Perez, D. Armentano, E. Pardo, J. Am. Chem. Soc. 2018, 140(28), 8827-8832.

[10] a) L. Ma, W. Li, H. Xi, X. Bai, E. Ma, X. Yan, Z. Li, Angew. Chem. Int. Ed. 2016, 55, 10410-10413; b) C. C. McAtee, P. S. Riehl, C. S. Schindler, J. Am. Chem. Soc. 2017, 139, 2960-2963; c) S. Niyomchon, A Oppedisano, P. Aillard, N. Maulide, Nat. Commun. 2017, 8, 1091; d) R. B. Watson, C. S. Schindler, Org. Lett. 2018, 20(1), 68-71; e) E. J. Groso A. N. Golonka, R. A. Harding, B. W. Alexander, T. M. Sodano, C. S Schindler, ACS Catal. 2018, 8(3), 2006-2011; f) H. Albright, P. S. Riehl, C. C. McAtee, J. P. Reid, J. R. Ludwig, L. A. Karp, P. M. Zimmerman, M S. Sigman, C. S.; Schindler, J. Am. Chem. Soc. 2019, 141(4), 16901700

[11] a) M. Sliwa, K. Samson, M. Ruggiero-Mikołajczyk, A. Zelazny, R. Grabowski, Catal. Lett. 2014, 144, 1884-1893; b) J. R. CabreroAntonino, A. Leyva-Perez, A. Corma, Angew. Chem. Int. Ed. 2015, 54(19), 5658-5661.

[12] a) P. G. Gassman, S. J. Burns, J. Org. Chem. 1988, 53, 5574-5576; b) T. Yamamoto, T. Eki, S. Nagumo, H. Suemune, K. Sakai, Tetrahedron 1992, 48, 4517-4524; c) S. Nagumo, A. Matsukuma, H. Suemune, K Sakai, Tetrahedron 1993, 49(46), 10501-10510; d) H. Suemtme, O Yoshida, J. Uchida, Y. Nomura, M. Tanaka, K. Sakai, Tetrahedron Lett. 1995, 36(40), 7259-7262.

[13] For a review see B. S. Kumar, A. Dhakshinamoorthy, K. Pitchumani, Catal. Sci. Technol. 2014, 4, 2378-2396.

[14] R. Pérez-Ruiz, M. A. Miranda, R. Alle, K. Meerholz, A. G. Griesbeck Photochem. Photobiol. Sci. 2006, 5, 51-55; b) M. D'Auria, R. Racioppi, Molecules 2013, 18, 11384-11428.

[15] T. B. Mete, T. M. Khopade, R. G. Bhat, Tetrahedron Lett. 2017, 58, 2822 2825 .

[16] A. Corma, V. R. Ruiz, A. Leyva-Perez, M. J. Sabater, Adv. Synth. Catal. 2010, 352, 1701-1710.

[17] a) K. Prantz, J. Mulzer, Chem. Rev. 2010, 110, 3741-3766.

[18] Y. D. Gong, H. Tanaka, N. Iwasawa, K. Narasaka, Bull. Chem. Soc. Jpn. 1998, 71(9), 2181-2185

[19] Y. Zhao, D. G. Truhlar, Acc. Chem. Res. 2008, 41, 157-167.

[20] C. Coperet, F. Allouche, K. W. Chan, M. P. Conley, M. F. Delley, A. Fedorov, I. B. Moroz, V. Mougel, M. Pucino, K. Searles, K. Yamamoto, P. A. Zhizhko, Angew. Chem. Int. Ed. 2018, 57(22), 6398-6440. 


\section{Entry for the Table of Contents}

\section{COMMUNICATION}

$\mathrm{R}$

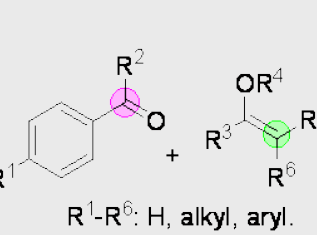

Montmorillonite K10

$R^{5}$

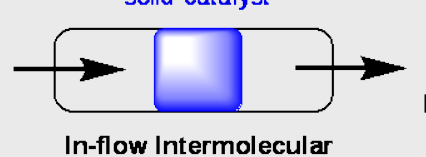

Carbonyl-Olefin Metathesis

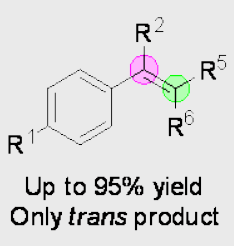

The intermolecular carbonyl-olefin metathesis between aromatic ketones/aldehydes and vinyl ethers is accomplished with not only simple soluble but also solid acid catalysts to give trans alkenes in high yields, multigram amounts and in-flow.
Miguel Ángel Rivero-Crespo, María

Tejeda-Serrano, Horacio Pérez-

Sánchez, José Pedro Cerón-Carrasco and Antonio Leyva-Pérez. *

Page No. - Page No.

Intermolecular Carbonyl-Olefin Metathesis with Vinyl Ethers

Catalyzed by Homogeneous and Solid Acids in Flow. 